This item was submitted to Loughborough's Research Repository by the author.

Items in Figshare are protected by copyright, with all rights reserved, unless otherwise indicated.

\title{
The CERME spirit: issues of quality and inclusion in an innovative
}

\section{conference style}

PLEASE CITE THE PUBLISHED VERSION

http://dx.doi.org/10.1007/978-90-481-9803-0

PUBLISHER

(C) Springer

VERSION

AM (Accepted Manuscript)

LICENCE

CC BY-NC-ND 4.0

\section{REPOSITORY RECORD}

Jaworski, Barbara, Joao Pedro da Ponte, and Maria Alessandra Mariotti. 2019. "The CERME Spirit: Issues of Quality and Inclusion in an Innovative Conference Style”. figshare. https://hdl.handle.net/2134/8798. 
This item was submitted to Loughborough's Institutional Repository (https://dspace.lboro.ac.uk/) by the author and is made available under the following Creative Commons Licence conditions.

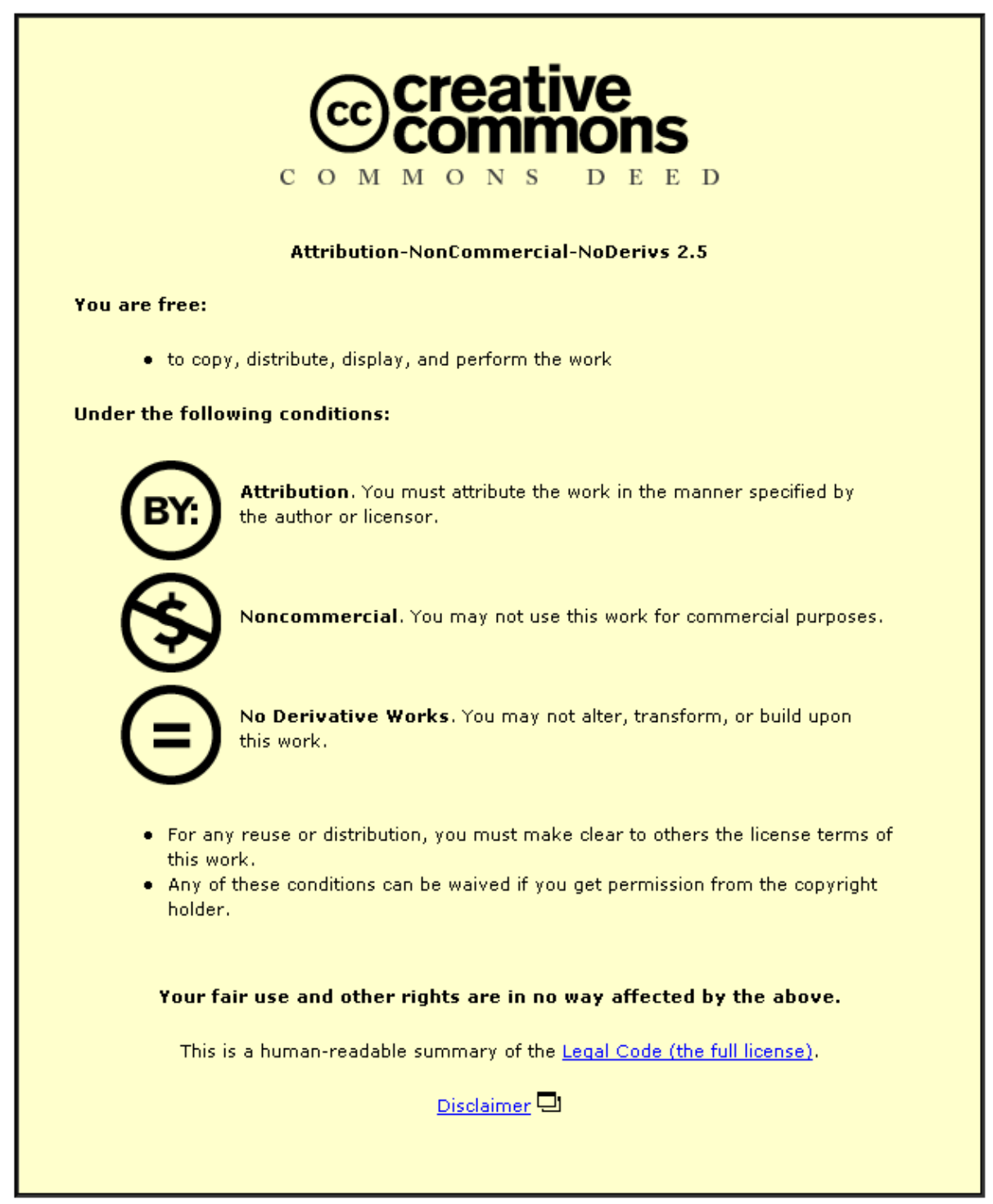

For the full text of this licence, please go to: http://creativecommons.org/licenses/by-nc-nd/2.5/ 


\title{
The CERME Spirit: Issues of Quality and Inclusion in an Innovative Conference Style
}

\author{
Barbara Jaworski - Loughborough University UK \\ Joao Pedro da Ponte - University of Lisbon, Portugal \\ Maria Alessandra Mariotti - University of Siena, Italy
}

This chapter presents findings from an analysis of data from participants in a bi-annual international mathematics education conference with regard to the practical realization of objectives relating to inclusion and quality in the conference. The chapter presents the context and objectives of the organizing Society and its interpretation of objectives in operationalizing a conference. It examines, theoretically, issues relating to inclusion of participants and quality of scientific work in the context of such a conference. It presents findings related to analysis of three sources of data - evaluation questionnaires from participants at the end of a conference, interviews with participants during a conference, and comments from group leaders written during and after a conference. Finally it synthesizes from issues raised and relates these to theoretical issues, presenting a tentative framework for creating and evaluating a conference which has principled objectives with relation to quality and inclusion.

\section{Introduction}

\subsection{The European Society for Research in Mathematics Education (ERME)}

In May 1997, a group of 16 scholars from different European countries met in Osnabrück, Germany, for three days to discuss the formation of a European society in mathematics education. In true European spirit, we decided that we wanted a society which would bring together researchers from across Europe, particularly including colleagues from Eastern Europe, fostering communication, cooperation and collaboration. We wanted a conference that would explicitly provide such opportunity. We wanted especially to encourage and contribute to the education of young researchers, recognizing that they are the future of our discipline. Thus ERME was born and began to take shape.

We decided on a two-yearly conference, or congress as it later became known, and the name CERME emerged - Congress of the European Society for Research in Mathematics Education. Considerable time was spent talking about the nature of the conference. How were we going to achieve the communicative, cooperative and collaborative spirit we envisaged? After some discussion, it was agreed that the conference should be more than just a platform for presenting and listening to papers. Many other conferences provided such opportunity. CERME should allow groups in a particular scientific area really to work together on their area of research, with sufficient time to get to know each other, to share and discuss their research and to engage in deep scholarly debate.

\footnotetext{
1 The authors of this chapter have been deeply involved in ERME development. Joao Pedro da Ponte was Chair of the Programme Committee for CERME 3 in Italy; M. Alessandra Mariotti was the local organiser of CERME 3 and a member of the ERME Board from 2005-2010; Barbara Jaworski was Chair of the Programme Committee for CERME 4 in Spain, member of the ERME Board from 2003-2008 and President of ERME, 2005-2008. Ponte and Jaworski were members of the group at Osnabrück initiating ERME.
} 
At the first CERME congress were held the early meetings of a committee that was to grow in later years into the ERME Board. The committee held open forum to seek views and formulate policy for ERME. Two principles, developed at the Osnabrück meeting, held clear importance, the first to encourage colleagues in Eastern Europe to become part of the society and secondly to support young researchers (young in research terms - not necessarily in age) throughout Europe. The ERME Board has worked hard over succeeding years to further these aims ${ }^{2}$.

During these years, evaluations and other testimonials suggested that we had initiated something exciting, significant and of important consequence for the future. Participants came from these events speaking of inspirational experiences. It seemed clear that the events generated something that we came to call the CERME Spirit. Based fundamentally on the three Cs, communication, cooperation and collaboration, the CERME Spirit was about the inspiration that derives from a serious scholarly tackling of ideas and concepts in key areas and of mathematics education research with colleagues from multiple nations, facilitated by the group design of the events.

The group design was not without its critics. Some felt constrained by the requirement to spend a conference, largely, in just one group. However, the group work would be seriously disrupted if participants were to hop from group to group, not engaging seriously with the work in any one. Some suggested that perhaps planning could allow participants to take part in two groups, so that engagement in both could be serious. Such ideas have been considered by the ERME Board and Programme Committees but so far we have remained faithful to the initial conception. Many participants have said in evaluation of the events that the opportunity to spend serious time in one group allowed them to really get to know researchers from other countries, and that this contributed significantly to the depth of thinking that was possible.

There are two important issues with which we have been grappling in CERME and YERME over the years: the quality of scientific work in a group related to papers accepted for the conference and published in the proceedings and the inclusion of all people who wish to attend. ERME aims for a high scientific quality of work, reflected in the reviewing and acceptance of papers. Attendance for most delegates requires that they present a paper, and not all papers meet high criteria on quality. To participate people need to be able to communicate and engage with the scientific discourse, and the language of events is English, as the only workable common language. However, it is recognized that many participants are disadvantaged by having to work in English. Language is also a factor in writing papers as well as in communicating at the conference. We need to address what exactly we mean by 'scientific quality' and what is entailed by 'inclusion' We recognize that both terms are deeply embedded sociohistorically in the mathematics education research community with its journals and conferences, and its written and unwritten rules of engagement. ERME, as a still young society, is consciously developing norms and seeking to influence research communication.

At this time in the life of ERME, we have collected data from participants' perspectives on their experience and their associated expectations. In this paper, we present findings from our analysis of this data and offer a tentative prospective for the ongoing work of ERME.

\footnotetext{
2 It was decided to establish ERME legally with charitable foundation in the UK, and this is now finalised with a formal Constitution and Bye-laws. With a solid legal foundation, ERME is now seeking to develop a strong financial footing.
} 


\section{Locating concepts and concerns within a wider frame}

In dealing with issues of inclusion and quality within CERME conferences, ERME embarks on an equity agenda within a broader frame of social justice (Burton, 2005). This section will address the question of what such an agenda implies for a European Society and Conference. Atweh and Keitel (2007) suggest that social justice necessitates working for theorising its meanings, working both with and on the concept. We are working with the concept in every conference and through our analysis recognising issues. To work on the concept, to start to address what inclusion and quality mean in terms of ERME and CERME, this chapter also begins to construct associated theory. This section introduces the issues, Section 3 presents findings from data analysis and the final section offers a tentative theoretical frame and agenda for the future.

\subsection{A European Society and Conference}

As has been explained above ERME is European: although it does not exclude nonEuropeans, it seeks primarily to bring together mathematics educators from all the nations in Europe. This implies an agenda of including all such mathematics educators, and we address what this means in the European context. We, European mathematics educators, work within the European Union and countries closely associated with that union. So, part of the inclusive agenda is about uniting, bringing together, sharing our scholarship, developing common understandings, respecting diversity. The three $\mathrm{Cs}$, communication, cooperation and collaboration, leading to the CERME Spirit, capture elements of the agenda

Communication is about talking to each other in ways that enable sharing and understanding of ideas and traditions that go beyond the superficial. Cooperation implies working together, going beyond communication to see how different perspectives and practices can illuminate issues and concerns, and open up new possibilities for addressing national agendas.

Collaboration means working together to create new agendas with initiatives that cross national boundaries and build cross-national, European identities. Atweh, Clarkson and Nebres (2003, p. 224) quote Hargreaves (1994, p. 45) who writes "one of the emergent and most promising meta-paradigms of the post-modern age is that of collaboration as an articulating and integrating principle of action, planning, culture, development, organisation and research" (emphasis in original). Atweh et al. comment as follows.

The limited resources in some countries imply that they are more likely to copy or import ideas from the more developed regions and countries rather than to critically and empirically reflect on their appropriateness to their local context (p. 224)

and

Collaboration should be constructed to empower individual countries to be self-reliant rather than to increase their dependency on ideas from more developed nations. (p.225)

In mathematics education research and practice particularly we have seen ideas from certain countries permeating the research agendas of others - for example with respect to the United States reform movement in schools and the associated NCTM standards (NCTM, 1989); and in respect of outcomes of international comparisons such as TIMSS, where countries around the world have looked to countries of South East Asia to learn how to achieve arithmetic success (Jaworski \& Philips, 1999). A challenge for ERME/CERME is to provide a forum for collaboration in which "an articulating and integrating principle" (Hargreaves, cited in Atweh et al, 2003, p. 224) can be achieved with open, respectful and non-hegemonic partnership between participants.

There are various issues associated with such an aim. In Western Europe, we have a number of (relatively) rich nations whose mathematics educators have had the privilege of travelling 
to international meetings and conferences over several decades. Their diverse traditions are well known (if not well understood) by all. A variety of conferences have provided opportunities for participants to hear the theories and approaches of others and to think about implications for their own research and practice. Despite such communication, we see little evidence of collaboration between national traditions on any substantial substantive scale. In Eastern Europe, the picture is different. Only relatively recently have borders been open for communication. Economic resources tend to be much less available for travel and participation beyond national boundaries. Mathematics Education research itself has barely started to exist within some Eastern European countries. It is of course inappropriate to generalise.

The relation of mathematics education to mathematics is one factor which varies considerably across Europe. In some countries (for example the UK and Portugal) mathematics education research has been largely the province of mathematics teacher educators working at primary and secondary levels, often in university departments of education (not mathematics), although there are notable exceptions. In some countries (for example Italy and France) many mathematics education researchers are themselves mathematicians, teaching mathematics at university level. Nevertheless, research in mathematics education has a very different character from research in mathematics. Indeed mathematics education is a different discipline from mathematics, which is not always understood by mathematicians. This has led to conflict between mathematicians and mathematics educators in some countries. In countries where mathematics education as a discipline is not well developed there can be confusion as to what research in mathematics education means at all. For example, one CERME 6 participant wrote on the evaluation questionnaire: "The conference was very theoretical - I am not used to this in my country (used to Pure Maths)". ERME is currently pursuing links with the European Mathematical Society (EMS) in order to develop a relationship with mathematicians in Europe.

\subsection{Why did we need another conference?}

It is a legitimate question. We can name several other international conferences which European Mathematics Educators can and do attend and to which all Europeans are welcome such as ICME, PME and CIEAEM. ICME, the International Congress of Mathematics Education, is the four yearly congress of ICMI, the International Commission for Mathematics Instruction with a membership from 72 countries. ICME attracts thousands of delegates from a variety of constituencies in mathematics education (including teachers, educators and researchers). It is not primarily a research conference. It imposes a solidarity tax on delegates to subsidise attendance from less affluent countries (Atweh et al, 2003, p. 192). PME, the annual conference of the International Group for the Psychology of Mathematics Education is a research conference. It welcomes research reports from any mathematics education researcher in any country and the main substance of the conference is presentation of research reports. Submitted papers are rigorously reviewed and accepted or rejected. Rejection often means that the authors do not attend the conference since conference funding depends on paper acceptance and publication. CIEAEM, the International Commission for the Study and Improvement of Mathematics Teaching, is multilingual; it focuses on teaching mathematics and welcomes teachers and others (Atweh et al, 2003, p. 191). It is not a research conference. Atweh et al (2003, p. 191) quote the Manifesto 2000 of CIEAEM as suggesting that a challenge for the whole international mathematics education community is "how can communities with different political, cultural and social conditions make ways to learn from each other more productively?" This challenge is overt in ERME.

So, how is CERME different from these other conferences? CERME is first of all a research conference in mathematics education, which distinguishes it from ICME and CIEAEM. It 
differs from PME in its structure around working groups. The idea is to get away from oral presentations towards work which fosters the three Cs in mathematics education research between group participants. Communication and cooperation have been visible is most CERMEs so far, and we are now starting to see collaborative initiatives across national boundaries (e.g., Prediger, Arzarello, Bosch, \& Lenfant, 2008).

\subsection{Equity agendas in ERME}

In considering equity, it seems important to emphasise the difference between equity and equality in educational practice. Zevenbergen (2001) has expressed this as follows:

Equity refers to the unequal treatment of students (or people more generally) in order to produce more equal outcomes. In contrast equality means the equal treatment of students with the potential of unequal outcomes. (p. 14)

In consideration of social justice in classrooms, Cotton (2001) writes, "the concept of social justice represents a shift in thinking away from equality ... [since equality]... does not easily accept and value difference" (p.28). So, for an equitable approach towards organising a conference, we need attention to those factors which do or could disadvantage some (potential) participants, and moreover, a policy towards encouraging certain groups of people for whom participation is problematic.

Atweh (2007) reports from a discussion group at ICME 10 (2004, Denmark) on the topic of international cooperation. The topic group organisers identified certain barriers to international contacts which included financial, language, and voice. The first two of these have been part of ERME consideration from the beginning. Recognising the likely financial disparity between the two groups mentioned above and other participants, ERME has, to date, invested most of its funds (gained from members' fees and profit on conferences) into financing summer schools for young researchers ${ }^{3}$ and supporting participants to CERME, particularly from Eastern Europe. The available funds have necessarily limited what is possible. Attempts to build up a 'support fund' from voluntary contributions have had only very minor success. So, it may be that a 'solidarity tax' on ICME lines is called for. Regarding language, while English is the language of the conference - a policy decision agreed at an early stage, which might of course be challenged - group leaders are encouraged to find ways of using other languages in working groups to facilitate full participation. So far practice has been ad hoc with differing reports on success or otherwise. It is an area for further consideration and possibly policy reconsideration.

The issue of 'voice' is related to language but goes beyond language to issues of culture, power and domination. Atweh (2007) reports from the discussion paper in the group at CERME 10.

Voice: collaboration between educators with varying backgrounds, interests and resources may lead to domination of the voice of the more able and marginalisation of the less powerful (Atweh, Boero, Jurdak, Nebres \& Valero, 2008, p. 445).

Although language can be a dominating factor, domination extends potentially beyond language per se. Atweh, quoting the leaders of the discussion group, emphasises another factor that relates strongly to the issue of voice. It concerns "missionary attitudes" of some participants in relation to preferred terminologies and their hegemony over ideas, recognising that the result can lead to "a patronising relationship which does not respect and value the diversity of the parties involved". They suggest, "Instead, an attitude of humility and openness to learn from each other should be the basis of international co-operations" (Atweh,

\footnotetext{
3 These are YERME events - Young-researchers in ERME, known as the YESS 1,2,3,4 \& 5, taking place in alternate years to the CERME conferences.
} 
et al., 2008, p. 446). The group structure at CERME is designed to enable participants to go beyond the presentation of papers to discuss ideas and issues and really work cooperatively on the substance of the topic. However, the focus of a group depends on both the papers received and the directions decided by group leaders. It is possible that domination of ideas by certain areas of scholarship in particular parts of Europe could be implicit in group work and remain unchallenged because the dominant voices are those promoting the particular ideas. Gates and Jorgensen (Zevenbergen) refer to Bourdieu's concept of habitus to express this as

Thus the field ... in which the participants engage recognises and conveys power to those whose habitus is represented and privileged in the field. (p. 164)

We look now to the practical realisation of ERME and CERME aims and the issues they raise according to such equity agendas.

\section{Views of participants regarding the CERME activity}

\subsection{Data and its analysis}

In the registration pack for each participant in CERME 6 in Lyon, France a short statement explained that members of the ERME Board would be gathering information with regard to quality and inclusion in CERME conferences. It explained briefly the main aims of ERME and CERME and introduced issues relating to quality and inclusion. It's purpose was both to raise awareness and to promote responses. At the end of the conference, two questionnaires were administered to participants: the first to all participants for evaluation of the congress, with a specific question addressing quality and inclusion as follows:

Balance of scientific quality and inclusion in your group: please give us here your views on balancing quality and inclusion (see statement in registration pack).

The number of questionnaires returned was 210 out of a participation of about 450 , thus just less than half. The second questionnaire was to group leaders, asking for written reflections on their experiences in organising a group at the conference, focusing specifically on issues of quality and inclusion. Out of a total of more than 45 group leaders, 13 responded from 9 out of 15 groups. Their responses addressed the review process, selection of papers, help given to (less experienced) authors to improve papers, language difficulties, and inclusion of papers in the conference proceedings. In addition, five interviews were conducted with CERME 6 participants (including two $\mathrm{PhD}$ students and three researchers with university positions) on their experiences at CERME and particularly their experience of the review process.

Analysis has involved reading carefully the written comments and listening to the interviews; categorising them in relation to emerging factors. To achieve categorization, questionnaires were organized according to working group and each written comment was assigned to a category that sought in some way to describe its content. Some touched on several issues and were assigned to more than one category. Particular comments are fed back to group leaders, although here we do not refer to specific groups.

A few participants did not notice the statement in the registration pack and in their questionnaire asked - "WHAT statement?" It could have made a difference to responses whether or not the respondent had read this statement. Some of the responses have a neutral or analytical tone, but most of them are either overtly positive or negatively critical. Many comments were of a telegraphic nature - participants may have offered a quick evaluative comment without deeper thought or analysis. The data sets themselves are limited by those who chose to respond: the findings come from returns from only about half the ERME population at one conference. Within these returns, some participants chose to make no comment on the key question on quality and inclusion. Some responses are ambiguous and 
their allocation to a category is done on the judgment of the researchers. Those doing the analysis are committed ERME members, active in ERME since its inception. While this allows an insider view of issues and concerns, it might also lead to an overly insider picture of what is offered.

We have organized our presentation of issues thematically, drawing on all the data sources where they offer contributory evidence. Where a quotation is unattributed, this means it is taken from a participant questionnaire; otherwise its origin is stated.

\subsection{Themes and issues}

Before a conference, the Programme Committee decides what groups to include and invites group leaders. Group leaders initiate a call for papers and organise a review process; they decide on accepted papers and plan a programme of work for their group. Papers accepted for the conference are published on the internet and members of a group asked to read them in advance. Guidelines suggest that oral presentation will occupy only a minimum of group work, perhaps allowing authors of a paper no more than 5 minutes to present their key ideas/issues. After the conference, selected papers are published in the conference proceedings. Further work on a paper may be required before it can be accepted for publication. Some papers are accepted only for the conference, but not for publication.

From the perspectives of participants, the areas of CERME operation promoting most comments are the groups in which most conference participation takes place, and the review process through which papers are selected for work at the conference and publication in the proceedings. In the following subsections we take up issues in these areas relating to inclusion for all, scientific quality and the three Cs.

\subsection{The review process and acceptance of papers}

CERME guidelines suggest open reviewing in which authors and reviewers are known to each other and communication can take place between authors and reviewers. They suggest two levels of acceptance: (1) for presentation at the conference and (2) for inclusion in the proceedings. Further work may be asked for at either or both of these levels. The two level process has evolved through several conferences in an aim to include as many people as possible at the conference and also to ensure a high quality of published papers after a conference. In theory this is to achieve a quality-inclusion balance.

There were positive comments about the value of the review process and its contribution in enabling participants to improve their papers and, additionally, in providing experience of reviewing.

Researchers also want to have their work published - perhaps inclusion can help them to achieve this.

I think that it is a good idea to do the review process, first of all, because it makes more connections among the members of the working group. So I am obliged to read the work of my colleagues with more thorough, more interest, more accuracy. And it makes, I think it is good experience for someone who has not done a review before. (Interviewee)

In some cases the nature of reviews was criticised as being too short, as containing dubious judgments, or as lacking critically helpful comments and questions.

The review I got back for my paper was very very short. It only said ... . Goal was mentioned, OK. Methodology was mentioned, OK. For the Proceedings [the review was] also very short. So I had to adjust nothing. I don't think it was that good. No difference at all for level 1 and level 2. (Interviewee) 
There were two reviews. One of them had a very helpful suggestion which was about "explain a bit more about the tasks". It was a small but very helpful suggestion. But I don't think it had anything - I wished it would have more questions. I think ... . The other was very unethical. One was completely uncritical, the other had some comments about small details. But no big questions - there was nothing in depth to demonstrate any real deep engagement with the paper. Neither one. (Interviewee)

Although not stated, we suspect that these were not named reviews, so no further communication was possible.

In some cases inclusion was interpreted as meaning that papers were accepted without critical consideration, leading to variable quality, "Too much inclusion - not enough selection". Some authors would have preferred a more critical or "rigorous" review of their paper:

Inclusion is more than having a paper accepted - need to feel it is valued - needs a more rigorous review process.

Balance between being inclusive or high standards - I think that the process of achieving that balance is exactly right - the participants reviewing the paper of the other participants. But perhaps there could be a bit more support for the reviews, to be more critical. With some helpful suggestions, I think quality would improve. (Interviewee)

I think some form of giving people permission to be critical and some sort of encouragement. Some of the papers in our subgroup are of questionable scientific quality. (Interviewee)

So, interpretations of inclusion that lead to uncritical acceptance of papers are inappropriate. The quality of papers is important for all participants. The issue here is how to help authors strengthen weak papers so that they are of sufficient quality and so that authors develop their own critical strength.

There were positive comments about the two level review process, some suggesting that only group leaders should do the final review;

Review process before conference should be for presentation in conference. For publication Chairs should decide what papers to include.

However, the option of have a paper accepted for presentation but not for the proceedings was seen to prevent some people from attending the conference, therefore running contrary to aims for inclusion. One group leader wrote that papers not accepted for the proceedings were withdrawn since "people cannot get financial support if a paper is not accepted for the proceedings". The importance of having a paper published was emphasized.

The research community at large does not know what happens between these four walls.

But the research community may look at the Proceedings. The maths education world is stressful. [In the proceedings] you know, your paper is permanent. To preserve academic reputation the papers should have a careful publication in the proceedings. (interviewee)

Some group leaders commented that papers outside the field of the group or of low quality were rejected, or recommended for resubmission as posters. Leaders spoke of trying hard to be inclusive of papers - to include as many as possible (often with no mention of quality). One said that they included papers with "severe weaknesses as long as there was an interesting idea". One leader wrote "Being all-inclusive and academically qualitative are $a$ priori incompatible".

Several leaders spoke of giving help to the less experienced and of being "more severe" to authors from well-represented countries. Some spoke of their organization of the review 
process, making decisions as a team. One group leader (A) said the following about her reading of reviews.

As I am reading through the reviews of papers as part of our 'second editing' stage, I want to share an observation about the different styles of reviews .... I notice that some reviewers use the sections on the form to summarize the content of the paper, but make little evaluative comment. This is useful for the group organizers when they see the reviews and are making decisions about the overall structure of the sessions - but it is of little value to the authors. In contrast, other reviews consist of evaluative comments, but may not give any indication of the content of the paper. ... This may be of more use to the authors, but is less helpful for the group organizer who wants to know something about the paper. (Group leader)

Another (B) spoke of her experience of using the process as part of the leadership team for the group.

[The group coordinator] carefully divided all papers in four (the leader and the three coleaders). Each of us had to review four to five papers together with two other participants of the group. At the end of the review process, each of us made a summary review for each of the papers that we were responsible for, studying first the other two reviews for each paper. In the case that contradictions appeared in the reviews, we invited the other leaders to study the article and express their opinion. If the majority of us agreed to a certain decision, then the group leader adopted that decision. Then we sent only the summary review to the corresponding author. Following the three $\mathrm{Cs}$ we tried to include most of the papers in the presentation of the papers. We only rejected a paper which did not meet the scientific guidelines for writing a research paper. (Group leader)

The comments overall suggest aspects of the review process that are not achieving the aims expressed in CERME guidelines. The two quoted above from group leaders (A) and (B) suggest details of the review process that seem to need more attention. For example, group leader (B)'s comment mentions that 'summary reviews' were sent to an author, seems to go against the suggested open process allowing communication between author and reviewer. The nature of a review, despite guidance on the review form, does not always satisfy both the needs indicated by group leader (A). How to bring the whole review process closer to CERME aims and the written guidelines seems to need further consideration.

\subsection{Group activity and participation}

Although a conference includes keynote presentations and other plenary events, the major part of any delegate's participation is as a member of their selected group. It is likely that they have a paper accepted by the group, or a poster. This will have been published on the internet along with others for the group and participants are asked to read these papers before the conference. They can also read papers for other groups if they wish. Group leaders can plan activity on the assumption that participants have read the group papers.

\subsubsection{Group size and the number of papers}

CERME 6 had about 450 participants and 15 groups; group size varied from 8 to about 70 participants, with slightly fewer accepted papers. Papers may be up to 10 pages in length, so if a group has more than 20 papers the reading task is considerable. One group leader wrote of having 54 papers and 15 posters, another of 55 papers. One solution would be to increase the number of groups, but this places pressure on facilities and resources. A group can be split into smaller groups for at least part of their work but may not have the availability of a separate room for each subgroup. These factors raise a variety of issues for group work and participation. Respondents commented that the size of a group affects what is possible, 
"participation of all was not easy", that it was hard to read all the papers, and a result was "poor (not in depth) scientific discussion with no clear questions" and "more small group work needed". Despite these practical problems some respondents reported that inclusion was "at a high level".

One of the interviewees indicated that the problem went beyond the possibility to read all the papers to the diversity of content and depth of focus.

I think there are some working groups that are too big. They have too many articles. Not because it is a problem reading them. But to keep track of so many articles that are not always so homogeneous. It is interesting to have a broad variety of topics but if it is too much it may be difficult to keep things together. So, I would prefer something smaller and discuss more thoroughly. (Interviewee)

Group work is constructed around the papers received and objectives for inclusion suggest that most of these papers will be accepted for presentation. Group leaders therefore have a considerable task in constructing a unifying programme of work. There seems to be a need to give time to each paper, and with 35 papers, even five minutes per paper is very significant. One comment pointed out that " 5 -min presentations need a quick change of focus between them", indicating issues of transition when many papers are included. Transitions between papers need to make clear links to themes within the work of the group. If participants are unable to keep track of ideas, this might suggest that the programme is not achieving its aims. Charting a scientific path through such diversity is a problem for group leaders and not everyone will agree with choices made.

\subsubsection{Organisational factors}

Each group had three or four designated leaders, each one from a different country. One leader was designated as Group Coordinator with the main responsibility for the group. Group coordinators were invited by the PC, and other leaders were decided by the PC in discussion with the coordinator. Comments from participants were overwhelmingly positive about the work and organisation of group leaders, for example, "First class organization from which authors could learn". Most recognized the importance of the work of group leaders and its demanding nature.

However, some comments criticized organization as "erratic", suggested that group leaders "need to control people who dominate discussion (such as English speakers)", showed "unfair handling of time and papers" and put "too much focus on individual papers rather than big ideas". Some comments suggested that advance communication of the methodology of the group would have been helpful, especially for participants who had not sent a paper, and who had therefore not received prior details of group work. Such comments all suggested feelings of exclusion at some level, although there is an element of not being able to please everyone.

\subsubsection{Group work - views on inclusion and scientific quality}

In the evaluation questionnaires, comments revealed differing perceptions of the terms and concepts of quality and inclusion. In some cases, the words were used with little further qualification (e.g., "everyone included", "inclusion good", "very inclusive", "inclusion not sufficiently addressed", "over-inclusive"), as if the concept is well understood and the associated judgment unproblematic. Further remarks provided insight into what was understood. For example, "discussion friendly and inclusive", "encouraging and critical". Comments included "good help with English" and "too inclusive - poor English accepted" (the last two comments from the same working group). We therefore recognise a difficulty of interpretation in our analyses. Although seemingly positive comments on inclusion greatly 
outnumbered the seemingly negative ones, without further illumination on the nature of judgment, it is hard to generalise.

The question had asked about "balance" so many comments made a comparison. Although the majority of comments suggested a good balance, "everyone included - quality high", "excellent in both [Q \& I] - newer researchers felt confident - supported by small group discussion", some (also) suggested that inclusion led to a reduction in quality:

Inclusion good, but therefore scientific quality was very variable.

Inclusion implies a generally poorer quality of paper.

Scientific standards should not be reduced to expand possibility of access.

Such comments reveal not only perceptions of an inverse relationship between quality and inclusion but also the differing values of participants. Some comments qualified the nature of a good balance.

Discussion on each paper enabled inclusivity and movement of papers towards higher quality through richness of critique.

Certain comments referred to inclusion of participants in group activity and dialogue and also to the ways in which accepted papers were addressed in a group. One interpretation of many of these is that inclusion relates to participant interaction in the social setting of the group and quality relates to the nature of papers, the rigour applied to paper acceptance and the ways in which papers were addressed in the group.

Some high quality papers, some very poor papers - better to raise quality even at the expense of inclusion.

Too strong on quality. One young researcher had paper rejected - it would have helped him to have it discussed.

The quality of discussion within a group was the focus of many comments, some suggesting a high quality ("lively" and "sophisticated"), with "experienced researchers moving talk into deeper reflections", and "Supportive and friendly, with penetrating remarks in response to papers". Others suggested that scientific discussion was poor with "not enough depth" and "Not all key ideas of papers discussed". In one group the level of discussion was judged to be high, so that "newcomers could not keep up with the standard of the group".

Some comments referred to how oral presentations of papers were conducted in a group. A significant number suggested that, despite recommendations, there was a substantial degree of oral presentation. For example, "too much paper presentation - more time should be given to small group discussion" and "work was almost entirely presentations", with "too much repetition of what is already known", and "not enough time for discussion". This contrasted with other comments: "no paper presentations", "active taking part", and "at least 50\% discussion maintained". We note that the comment "not enough time for discussion" could have meant that paper presentation did not allow time for discussion, or it could have referred to the number of papers that were included in that group (or both).

We are aware that language difficulties are more easily overcome in a prepared presentation, and that some participants prefer to take that opportunity to feel free and confident to talk. This observation highlights the importance of managing discussion with genuine opportunity for those who have difficult with English. Surprisingly, there were not many written comments about language. The few comments expressed, not included elsewhere, were as follows:

Language difficulties and differences in theoretical approach made it difficult to take part in discussion. 
Despite being a supportive group, those struggling with English don't have good participation.

Non-English speakers had difficulty to join in and voice ideas.

English speakers talked too much.

A difficulty may be that those experiencing difficulty with English are also not able to express their views on an evaluation form.

Perhaps the strongest message coming across in this section is the diversity in perceptions of group work. Even within a single group, in some cases comments seemed largely in agreement while in others there were (widely) differing views. It therefore seems important to see group activity through these alternative visions when preparing the programme of work.

\subsection{Issues raised by group leaders}

It seems appropriate in this last subsection to give the final voice to group leaders. One very positive comment reported as follows:

We had four productive days in a friendly atmosphere. Sure some discussions may have become a bit heated, but that is only natural and they were constructive still. As for language, sure there were some participants who had English difficulties, but then other participants would help to translate and it all worked out fine. (Group Leader)

Another commented specifically on the two-stage review process and the decision as to whether a paper would be published in the proceedings:

According to CERME guidelines, the accept/reject decision should have been communicated before the conference, both with regard to discussion at the conference and with regard to the post-conference proceedings. In fact, following our WG call for papers, we did not communicate the decisions about the publication in the proceedings before the conference. We preferred to discuss the accepted papers in our WG and later to fix the decision with another review process, taking into account all the remarks and comments. This provided opportunity to improve the papers (in particular papers needing help) following the path of "quality and inclusion". I received no complaint about this line from the participants. (Group Leader)

And finally:

The work in many of the WGs has been a series of paper presentations. The Board needs to be clear that this is not an acceptable format. In addition it might be necessary to provide a list of acceptable formats that the group coordinators could indicate the one they use or present their alternative format for organizing the sessions. In our group we had 3 different formats that are not traditional papers presentations. I would be happy to share these if needed. A proper plan for organizing the sessions might be a requirement for a Chair to be selected. (Group Leader)

The last two comments reflect the thoughtful hard work of group leaders. They also point to a possible tension between leaving group leaders with freedom to construct their work according to their own expertise and professional judgment and requiring that they conform to some pre-given format designed to promote ERME aims and values. 


\section{Discussion of emergent issues and a tentative framework for further consideration}

\subsection{Synthesis of key issues and concerns arising from or supported by the data}

ERME starts from a position of seeking equity, particularly with regard to inclusion of young researchers and delegates from less affluent countries or countries with different traditions in mathematics education. Evidence shows that seeking for equity is both resource and policy based: shown in financial support and organizational structures. The issues that arise relate largely to the interpretation, or operationalization, of the organizational structures. The following list highlights the key points:

- Inclusion in recognized as overt in the group activity at CERME - largely this seems to be an affective perception of inclusion. Some participants see an inverse relationship between inclusion and quality of accepted papers and scientific debate.

- Quality, that is scientific quality, relates to the quality of accepted papers and the quality of scientific work within a group.

- Language is a key factor relating to both inclusion and quality, and perceptions differ with regard to ways of interacting in practice.

- The review process is key to issues of quality in accepted papers. It is interpreted differently from group to group so that outcomes lack consistency.

- The mode of group operation is also variable. Despite recommendations considerable group time is taken up by oral presentation of papers.

- Group leaders are widely praised and their work recognized and valued. It is difficult for them to rationalize ERME's aims for inclusion and quality.

- Key issues in conference organization are the number of people in a group and the number of accepted papers to be read and considered. High numbers of both lead to a significant burden on participants in preparation for group work, a significant factor in allocation of group time, and a serious challenge to a high quality of discussion and debate.

It is perhaps unsurprising that equity objectives are hard to realize, that participants will perceive their realization in differing ways, and that outcomes will raise issues for operationalization. While raising issues, criticizing outcomes and offering a critical perspective on experiences of inclusion and quality, there is overwhelming praise for the group leaders and their efforts to achieve effective group work. CERME is dependent on its group leaders and a critical review needs to take serious account of the contradictory forces they experience in doing their work. The comments received from the group leaders who responded reflect a deep awareness of issues and a sincere concern to address equity.

It is clear too, regarding policy in ERME, that the policy-makers (ERME Board and CERME PCs) have established both an overall vision and important working practices. These are seen both in terms of funding to provide support and guidelines for operational practice. Of course, a policy is indispensable although not a guarantee. The two practical concerns that stand out as being of significant influence on inclusion and quality are the review process and the size of groups. The review process is set out in the guidelines which have been modified and refined over the years. However, it is the review process in practice that matters, and this needs attention at a policy level.. The number and topics of groups is decided by each CERME PC. The number of 15 groups has emerged in consideration of a range of topics to fit with interests of participants and also the practical consideration of availability of 
conference rooms. The PC has no control over the number of papers submitted to a group, but they can learn to some extent from experience at previous conferences - some groups regularly receive a large number of papers. The possibilities for group leaders are severely constrained if they have many participants, too few rooms and inflexible accommodation. It is clear that such factors are of broad general importance.

\subsection{Getting beyond the organizational factors}

The essence of the tensions between inclusion and quality goes deeper than just the organizational issues, although these issues are significant in practice. Differences in experience and culture, mediated through language, have to be recognized and addressed. The expert and the novice, the western participant and the eastern participant have to be able to work together in non-reductionist ways. Atweh at al. (2003), writing about the outcomes of international comparative studies, suggest "Outcomes of such studies are also perceived as necessarily reductionist, as results cannot do justice to the very complex factors involved" ( $\mathrm{p}$. 12, our emphasis). To be non-reductionist, the balance between inclusion and quality within a group needs to take on a scientific nature that goes beyond (perceptions of) the scientific quality of the substance of the topic of the group. A theoretical perspective on this balance needs to take account of "the complex factors involved", and these go beyond organizational constraints.

Experienced CERME participants are aware of the expectation of inclusion within a group, and newcomers are drawn quickly into an inclusive way of being in an affective mode. There are almost no comments that suggest that group work was not friendly and welcoming, that participants were not (overtly) encouraged to take part and join in the discussions. Such welcoming encouragement might be seen as a first step towards being drawn in to a scientific depth of ideas. Participating scientifically can be related to what one knows and one's confidence in that knowledge. However, we recall here some of our discussion in Section 2.3 above: that "the field ... in which the participants engage recognizes and conveys power to those whose habitus is represented and privileged in the field". (Gates and Jorgensen, p. 164); that "collaboration between educators with varying backgrounds, interests and resources may lead to domination of the voice of the more able and marginalization of the less powerful" (Atweh, et al., 2008, p. 445); and that an attitude of humility and openness to learn from each other should be the basis of international co-operations (Atweh et al, 2008, p. 446).

It seems to us that those experienced in CERME, in their interpretation of inclusion, are aware of possibilities of privilege, domination and marginalization and are seeking alternatives. We see, demonstrated in group work and the comments of participants, manifestations of an "attitude of humility and openness". Group leaders and participants try hard to engage everyone and to avoid domination. The difficult challenges are those of interpretation and balance. When participants speak of inclusion being at the expense of scientific quality, they suggest that the balance does not achieve a sufficient depth of ideas or allow deeper scientific considerations to be debated. However there is no reason why a young researcher cannot enter into the deeper ideas and issues, or why researchers from widely different standpoints in mathematics education cannot seek the roots of their difference and debate them. The great challenge is how to achieve this.

Probably, most recognize that the first step involves communication, and here issues of language dominate. While it is hard to search for the key ideas and to express them, it is even harder if you are trying to do it in an unfamiliar language, or if you are trying to slow yourself down in recognition of your hearers' language difficulties. A consequence is that the 'key ideas' get diluted in the language exchange, or that those with power over language run away with words and leave others with little sense of what they are talking about. Either way, the 
ideas remain superficial at the cooperative level. So individuals may have deep ideas but these ideas do not get expressed in the 'cooperative frame'. We seek here to capture what it means to cooperate, and suggest that it is about breaking through the complex barriers not only of differing perspectives but also of the cultural and language differences which underpin them.

It is here perhaps that some consideration of the contribution of the papers is relevant. The papers, presented in written form in advance, offer key ideas according to their authors. The review process has both made a selection of papers that are relevant to the group and judged them to be of an acceptable scientific quality. Readers, in advance of group work, can take their time to understand the papers and gain access to the key ideas. They can expand their own visions and formulate questions and alternative perspectives in preparation for the group work. This reading is demanding, not only in tackling an overwhelming number of papers, but in getting to and distilling in some way the key ideas of the papers. The burden falls on the group leaders to identify and synthesise these ideas in order to construct a programme of work. It is here that oral presentations can be counter productive. A natural tendency is for the authors to try to tell the whole story of their research, rather than to get to the roots of what are the important ideas for the group. Indeed, it is very difficult for each individual author to perceive how their own key ideas, related as they are to many factors of culture, methodology and scientific frame, can fit with the wider interests and concerns of the group.

So, we come to the demands on group leaders. While appreciating the demanding task of reviewing and selecting papers, and composing a programme, it is nevertheless relatively easy to construct a programme in which each paper is addressed one at a time with some level of presentation and some discussion. It may be that links are made in transition between one paper and the next, or that papers are grouped according to some commonalities in their substance, theoretical, methodological, or context related. Much harder is to formulate a set of 'key ideas' and organize the group around these key ideas as themes for discussion and debate. Members of one CERME group spoke of being asked to prepare one overhead transparency on each of the set of themes in their group. Thus, the themes had been prepared by the group leaders in advance and communicated to participants, and participants had been asked to prepare inputs according to the themes. Work in the group centred on the themes, with all members making an input, but with no oral presentation of the actual papers. Without any judgment on the quality of the themes, it seems that this model offers a sincere possibility for cooperative engagement. There may of course be many other models that seek to reach the key ideas and provide opportunity to engage with them.

ERME recognizes and tries to get away from the traditional form of research conference which involves a succession of oral presentations of accepted papers, and tries to progress the field in terms of scientific cooperation, moving towards collaborative possibilities. To collaborate we need to break down the barriers and get to the essence of our substance before we can move forwards. One group at CERME has started to achieve this, evidenced by a cross-nationally authored paper, based on group work, published in a scientific journal (Prediger, Arzarello, Bosch and Lenfant, 2008). ERME needs to learn from such experience and use it to promote models of group work and debate their nature and success

\subsection{A tentative theoretical synthesis.}

So, finally, we seek a balance between inclusion and quality as expressed throughout this paper. A distinction may be drawn between more affective and more scientific characteristics of inclusion, although these are intricately linked in their influence on the outcomes of discussion and debate in a group. Without inclusion of an affective character, work towards scientific inclusion cannot begin. Scientific quality can be seen in terms of the scientific 
contribution of accepted papers and the scientific nature of discussion and debate. The essence of scientific quality is about reaching for the key ideas of substance in the scientific area of the group and having the possibility of deep engagement with these ideas.

The following conceptualization is offered as a tentative beginning to characterize inclusion and quality and to relate the characterization to the specific aims of ERME in terms of communication, cooperation and collaboration.

\begin{tabular}{|l|l|l|}
\hline Inclusion & $\begin{array}{l}\text { Quality } \\
\text { Having key ideas in the } \\
\text { Scientific area }\end{array}$ & $\begin{array}{l}\text { (Deep) engagement with } \\
\text { key ideas in the scientific } \\
\text { area }\end{array}$ \\
\hline Affective inclusion & Starting to communicate & $\begin{array}{l}\text { Developing cooperation in } \\
\text { engaging with debate }\end{array}$ \\
\hline Scientific inclusion & $\begin{array}{l}\text { A } \\
\text { Developing cooperation in } \\
\text { recognising ideas }\end{array}$ & $\begin{array}{l}\text { Enabling collaboration in } \\
\text { the development of key }\end{array}$ \\
\hline ideas and new shared \\
constructs
\end{tabular}

The two axes represent inclusion and quality. Inclusion is characterized in affective and scientific terms. The distinction is somewhat simplistic, but this is a starting point. Quality is characterized through 'key ideas' and their development. The key ideas need to be there for scientific quality to exist at all; they need to be engaged with for scientific quality to start to be overt in the group. Thus we might see there being progress right to left and up to down in the figure (again, perhaps somewhat simplistic), and hence from top left to bottom right in the figure.

The meanings of boxes A, B, C, and D are thus, briefly, as follows:

A: Starting to communicate: participants have read the papers, they are together with friendliness and sincere desire to work inclusively together. There are key ideas as recognized through the review process in the accepted papers. Activity and discussion begin to encourage communication related to the ideas where the objective is to know each other's ideas and relate them to each other.

B: Developing cooperation in engaging with debate: Group organization enables a focus on the key ideas. Friendly and considerate interaction, with attention to language enables participants to start to engage with the ideas. The emphasis is on including everyone, possibly at the expense of really probing scientific work.

C: Developing cooperation in recognizing ideas: Group leaders create activity to encourage a focus on getting participants engaged with the key ideas which are recognized. The emphasis is on reaching a quality of interaction relating to scientific ideas rather than on enabling critical inquiry into the essences of the ideas.

D: Enabling collaboration: Here we see deep engagement of a scientific quality with deep probing of ideas and corresponding critical debate. From here, collaboration can begin. 
It seems clear that for $\mathrm{D}$ to be possible, both $\mathrm{B}$ and $\mathrm{C}$ have to be achieved. This means dealing with all the organizational challenges recognized above, which is a far from trivial matter.

However, it could be that a theoretical perspective of this sort, of what is involved in achieving inclusion and quality in group work in CERME, can act as a basis for thinking about dealing with the challenges and conceptualizing in practical terms what we are aiming for in CERME.

\section{References}

Atweh, B. (2007). International interactions in mathematics education. In U. Gellert \& E. Jablonka (Eds.), Mathematisation and demathematisation: Social, philosophical and educational ramifications (pp. 171-186). Rotterdam, The Netherlands: Sense Publications.

Atweh, B. Clarkson, P. \& Nebres, B. (2003). Mathematics education in international and global context. In A. Bishop, M. A. Clements, C. Keitel, J. Kilpartick, \& F. Leung (Eds.), The second international handbook of mathematics education, (pp. 185-229). Dordrecht: Kluwer Academic Publishers.

Atweh, B. Keitel, C. (2007). Social justice in international collaborations. In Atweh, B., Borba, M. Calabrese Barton, A., Gough, N., Keitel, C., Vistro-Yu, C. Vithal, R, Internationalisation and globalisation in mathematics and science education (pp. 95-112). Dordrecht, The Netherlands: Springer.

Atweh, Boero, Jurdak, Nebres \& Valero (2008). International cooperation in mathematics education: promises and challenges. In M. Niss \& E Emborg (Eds.), Proceedings of the $10^{\text {th }}$ International Congress on Mathematical Education (ICME 10), July 4-11, 2004, Copenhagen, Denmark,.(pp. 443-447). Roskilde, Denmark: Roskilde University.

Burton, L. (Ed.) (2005). Which Way Social Justice in Mathematics Education. Westport, CT: Praeger Publishers.

Cotton, T. (2001). Mathematics teaching in the real world. In P. Gates, (Ed.). Issues in Mathematics Teaching (23-37). London: Routledge/Falmer.

Gates, P. \& Jorgensen, R. (2009). Foregrounding social justice in mathematics teacher education. Journal of Mathematics Teacher Education. 12, 161-170.

Hargreaves, A. (1994). Changing teachers, changing times: Teachers' work and culture in the post-modern age. London: Cassell.

Jaworski, B. \& Phillips, D. (1999). Looking abroad: international comparisons and the teaching of mathematics in Britain. In B. Jaworski \& D. Phillips (Eds.), Comparing Standards Internationally: Research and Practice in Mathematics and Beyond, (pp. 7-22). Oxford: Symposium Books.

National Council of Teachers of Mathematics (NCTM), 1989). Curriculum and Evaluation Standards for School Mathematics. Reston VA: NCTM.

Prediger, S., Arzarello, F., Bosch, M and Lenfant, A. (2008). Comparing, Combining, Coordinating - Networking Strategies for Connecting Theoretical Approaches. ZDM 40/2 pp. 163-340

Zevenbergen, R. (2001).Changing contexts in tertiary mathematics: Implications for diversity and equity. In D. Holton (Ed.), The teaching and learning of mathematics at university level: An ICMI study. The Netherlands, Kluwer Academic Publishers. 